\title{
Movements of Wild Pigs in Louisiana and Mississippi, 2011-13
}

Open-File Report 2014-1241 



\section{Movements of Wild Pigs in Louisiana and Mississippi, 2011-13}

By Stephen B. Hartley, Buddy L. Goatcher, and Sijan K. Sapkota

Open-File Report 2014-1241 


\section{U.S. Department of the Interior \\ SALLY JEWELL, Secretary}

\section{U.S. Geological Survey \\ Suzette M. Kimball, Acting Director}

\section{U.S. Geological Survey, Reston, Virginia: 2014}

For more information on the USGS — the Federal source for science about the Earth, its natural and living resources, natural hazards, and the environment, visit http://www.usgs.gov or call 1-888-ASK-USGS.

For an overview of USGS information products, including maps, imagery, and publications, visit http://www.usgs.gov/pubprod

To order this and other USGS information products, visit http://store.usgs.gov

Any use of trade, firm, or product names is for descriptive purposes only and does not imply endorsement by the U.S. Government.

Although this information product, for the most part, is in the public domain, it also may contain copyrighted materials as noted in the text. Permission to reproduce copyrighted items must be secured from the copyright owner.

Suggested citation:

Hartley, S.B., Goatcher, B.L., and Sapkota, S.K., 2015, Movements of wild pigs in Louisiana and Mississippi, 2011-13: U.S. Geological Survey Open-File Report 2014-1241, 11 p., http://dx.doi.org/10.3133/ofr20141241.

ISSN 2331-1258 (online) 


\section{Acknowledgments}

The authors would like to thank Dirt Piranha and Goatcher Wildlife for donations of trained capture-dog services and related equipment. Thanks are given to Cannisnia Plantation, Matt Rimmer Farm, Chad Courville of Miami Corp., Judge Edwards and Bill Broussard of Vermilion Corp., and local landowners and lessees Dennis Good and Dan Hidalgo, Sr., for providing access to study sites. The authors would like to express appreciation to local hunters Daniel Edgar, James Aucoin, Shane Boudreaux, Cody Fortier, Calen Mire, Joey Young, Parker Perot, Scotty Dickson, Skipper Dickson, Adam Goatcher, Kim Crochet, Brian Haupt, Kody Landry, Noel Bunol, Mike Fradella, Michael D. Fradella, Matthew Fradella, and Jonathan Fradella for logistical support and valuable advice during field work. Special thanks go to Walter Cotton and Scott Woodriff of the U.S. Department of Agriculture (USDA) Animal and Plant Health Inspection Service and Robert "Goose" Gosnell and John Dickson of the U.S. Fish and Wildlife Service for conducting field work. Thanks to Dwight LeBlanc of the USDA Animal and Plant Health Inspection Service and Dr. Jim LaCour of the Louisiana Department of Wildlife and Fisheries for reviews of the study plan and to Drs. Bronson Strickland and Bruce Leopold for their valuable comments in their peer review of the report. 



\section{Contents}

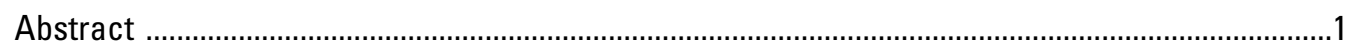

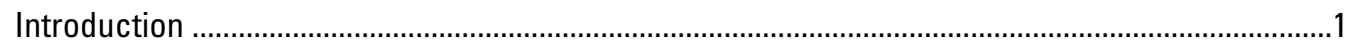

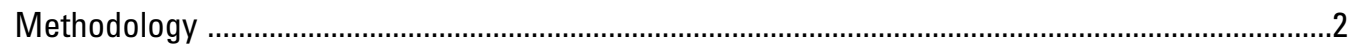

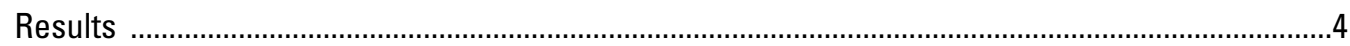

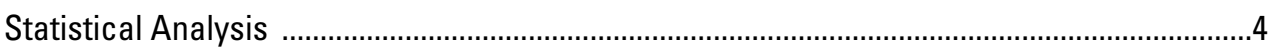

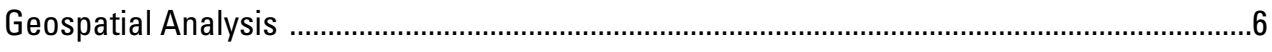

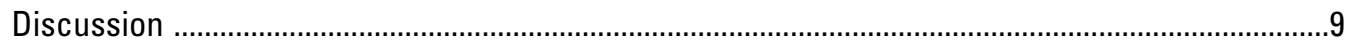

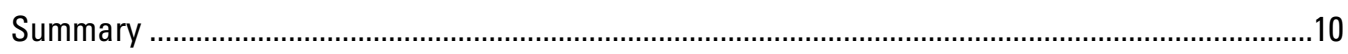

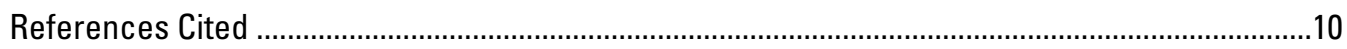

\section{Figures}

1. Map showing study area and sites of capture and release of wild pigs fitted with satellite GPS tracking collars during the 2011-13 study in Louisiana and Mississippi

2. Graph showing average distance traveled per hour by collared wild pigs and average air temperature by season during the 2011-13 study in Louisiana and Mississippi

3. Graph showing monthly average of distance traveled per hour by collared wild pigs during the 2011-13 study in Louisiana and Mississippi ..

4. Radar chart showing average distance traveled by collared wild pigs on an hourly basis during 24-hour periods and depicting diurnal effect in movement during the 2011-13 study in Louisiana and Mississippi

5. Graph showing regression with a 95-percent confidence band showing average distance per hour traveled by wild pigs relative to average air temperature during a 24-hour period during the 2011-13 study in Louisiana and Mississippi ..............8

6. Graph showing maximum distance traveled per hour by wild pigs with respect to gender and season during the 2011-13 study in Louisiana and Mississippi .9

\section{Tables}

1. Seasonal average distance traveled per hour by collared wild pigs and onsite air temperature recorded from hourly monitoring data during the 2011-13 study in Louisiana and Mississippi

2. Distance traveled per hour by wild pigs in interval frequency during the 2011-13 study in Louisiana and Mississippi 


\section{Conversion Factors}

SI to Inch/Pound

\begin{tabular}{lll}
\hline \multicolumn{1}{c}{ Multiply } & By & \multicolumn{1}{c}{ To obtain } \\
\hline centimeter $(\mathrm{cm})$ & Length & \\
meter $(\mathrm{m})$ & 0.3937 & inch (in.) \\
kilometer $(\mathrm{km})$ & 3.281 & foot (ft) \\
kilometer $(\mathrm{km})$ & 0.6214 & mile (mi) \\
meter $(\mathrm{m})$ & 0.5400 & yard (yd) \\
\hline & 1.094 & acre \\
\hline square meter $\left(\mathrm{m}^{2}\right)$ & Area & acre \\
hectare $($ ha) & 0.0002471 & acre \\
square kilometer $\left(\mathrm{km}^{2}\right)$ & 2.471 & square foot $\left(\mathrm{ft}^{2}\right)$ \\
square meter $\left(\mathrm{m}^{2}\right)$ & 247.1 & square mile $\left(\mathrm{mi}^{2}\right)$ \\
square kilometer $\left(\mathrm{km}^{2}\right)$ & 10.76 & \\
\hline & 0.3861 & pound avoirdupois $(\mathrm{lb})$ \\
\hline kilogram $(\mathrm{kg})$ & Weight & \\
\hline
\end{tabular}

Vertical coordinate information is referenced to the North American Vertical Datum of 1988 (NAVD 88) unless otherwise noted.

Horizontal coordinate information is referenced to the North American Datum of 1983 (NAD 83).

Time in this report is given as 24 -hour military time and is referenced to local time, including (if applicable) daylight saving time. 


\title{
Movements of Wild Pigs in Louisiana and Mississippi, 2011-13
}

\author{
By Stephen B. Hartley, ${ }^{1}$ Buddy L. Goatcher, ${ }^{2}$ and Sijan K. Sapkota ${ }^{1}$
}

\section{Abstract}

The prolific breeding capability, behavioral adaptation, and adverse environmental impacts of invasive wild pigs (Sus scrofa) have increased efforts towards managing their populations and understanding their movements. Currently, little is known about wild pig populations and movements in Louisiana and Mississippi. From 2011 to 2013, the U.S. Geological Survey investigated spatial and temporal movements of wild pigs in both marsh and nonmarsh physiographic regions. Twenty-one Global Positioning System satellite telemetry tracking collars were installed on adult wild pigs captured with trained dogs and released. Coordinates of their locations were recorded hourly. We collected 16,674 hourly data points including date, time, air temperature, and position during a 3-year study. Solar and lunar attributes, such as sun and moon phases and azimuth angles, were not related significantly to the movements among wild pigs. Movements were significantly correlated negatively with air temperature. Differences in movements between seasons and years were observed. On average, movements of boars were significantly greater than those of sows. Average home range, determined by using a minimum convex polygon as a proxy, was 911 hectares for boars, whereas average home range for sows was 116 hectares. Wild pigs in marsh habitat traveled lesser distances relative to those from more arid, nonmarsh habitats. Overall, results of this study indicate that wild pigs in Louisiana and Mississippi have small home ranges. These small home ranges suggest that natural movements have not been a major factor in the recent broadscale range expansion observed in this species in the United States.

\section{Introduction}

Wild pigs (Sus scrofa) are a major problem for land and resource managers in the United States because of the

\footnotetext{
${ }^{1}$ U.S. Geological Survey.

${ }^{2}$ U.S. Army Corps of Engineers.
}

enormous amounts of damage that these animals cause to natural and man-made environments. This exotic, invasive species is found in large populations on public (for example, Federal sites such as national parks and national wildlife refuges) and private lands in most States. Their high reproductive potential, ability to adapt to numerous environments, destructive foraging habits, and potential to function as disease vectors make wild pigs a challenging and serious threat to environmental, human, and financially important (for example, agricultural) resources in the United States (Mayer, 2009; Hamrick and others, 2011).

Kaller and Reed (2010) described wild pigs as the most prolific large mammal in North America; with adequate nutrition, their populations can double in 4 months. Comer and Mayer (2009) reported that wild pigs can reach sexual maturity as young as 3 months, and sows have been documented to be reproductively active as old as 14 years of age. Kaller and Reed (2010) also stated that sexual maturity in sows has been observed as young as 6 months; with a few sows birthing two litters per year and averaging 6 piglets per litter (ranges between 3 and 8 piglets), the population growth in many locations is exponential. On the basis of reproductive capacity, it has been estimated that wild pig populations can completely rebound from a 70-percent population removal in 2.5 years. Additionally, reducing only adult females up to 90 percent may not be effective because of the ability of young females (6-12 months old) to reproduce (Kaller and Reed, 2010).

In Louisiana and Mississippi, populations of wild pigs have existed since the 1500 s, when Spanish explorer Hernando de Soto, who traveled extensively throughout the Southeastern United States, brought pigs with his expedition (Hamrick and others, 2011). During the European colonization of America, domestic swine were allowed to range freely on unfenced lands to be recovered for slaughter, a common practice in Louisiana and Mississippi. No scientific investigation of the genetic composition of Louisiana or Mississippi wild pigs exists, with most assumed to be the descendants of domestic swine; however, hybrids of domestic swine and Eurasian wild boar are evident in several locales on the basis of pelage and morphology (Mayer and Brisbin, 1993). 
In the early 1900s, Eurasian wild boars (perceived by sport hunters as a more desirable hunting quarry) were introduced along with domestic swine by game ranchers and private hunting groups (Kaller and Reed, 2010). These releases extended the range of invasive wild pigs beyond the Southern and Western United States (Mayer and others, 2009; Kaller and Reed, 2010; Hamrick and others, 2011). Problems with wild pigs historically limited to the Southeastern States, California, Hawaii, and Texas now extend to many Northern States including Michigan, North Dakota, and Oregon (Hamrick and others, 2011). As a result, wild pigs are widespread throughout much of the United States, and their presence has been reported in 47 States. Wild pig damages to agricultural and forest lands are documented worldwide (West and others, 2009; Kaller and Reed, 2010); however, scientific studies of wild pig damages and movements in Louisiana and Mississippi are rare.

Even though wild pigs of the Southern United States have a prolific breeding capability as they do elsewhere, during the Great Depression (approximately 1930-40) and following decades, wild pigs were almost eradicated, except in those wards, parishes, and counties where government officials and local statutes protected pig free-range practices (Mayer and Moore-Barnhill, 2009). Wild pig populations have continued to increase even with the banning of free-ranging pigs (Mayer and Moore-Barnhill, 2009). Another contributing factor in wild pig population increases is the illegal release of Eurasian wild boar, wild pigs, and even domestic adult swine and piglets by hunters and game ranchers for sport hunting (Kaller and Reed, 2010).

Wild pigs are found in a wide variety of habitats in Louisiana and Mississippi, including coastal areas ranging from tidal marshes along the Gulf of Mexico coast to forested uplands in northern parishes and counties (Mayer, 2009). They prefer areas that provide access to water, cover, and a dependable source of food. In the Louisiana Chenier Plain (fig. 1), seasonal, heavy mast crops may often limit wild pigs to smaller areas, but human disturbance or lack of resources like food and escape cover may be the two greatest factors for their dispersal (Comer and Mayer, 2009; Mayer, 2009). Some areas where populations of wild pigs have not been seen in recent times will suddenly exhibit rooting, wallowing, and other signs of their presence (Kaller and Reed, 2010). Concurrent with increased dispersal in types of habitats and areas occupied by these animals in Louisiana and Mississippi has been an increase of types of damage that wild pigs cause. Elsey and others (2012) conducted a survey of Louisiana alligator farmers regarding alligator nest losses and found that more than half of the farmers reported losses of alligator nests to wild pig depredation. In 1 year (that is, 2011), there were 590 nests damaged or destroyed on 36 separate properties across the State, whereas only 7 nests were lost in all three prior surveys combined. Elsey and others' (2012) survey data of wild pigs damaging alligator nests, eggs, and habitats suggest loss of tens of thousands of dollars to landowners and managers each year. Besides the loss of alligator nests, in coastal wetlands of Louisiana and Mississippi, rootings of wild pigs impact subterranean flora and fauna while restricting the expansion of root zones of trees and plants, thus potentially exacerbating coastal erosion and land loss (Kaller and Reed, 2010).

While monitoring other species from U.S. Fish and Wildlife Service (USFWS) helicopters during the BP Deepwater Horizon oil spill in 2010, wildlife biologists observed a problem of wild pigs in coastal Louisiana (B.L. Goatcher, USFWS, oral commun., 2010). The wildlife biologists observed that invading wild pigs had encroached into new areas at an alarming rate, especially since the passage of Hurricanes Katrina and Rita, not only into marshland and farmland but also into sensitive wetland nesting bird habitat (B.L. Goatcher, USFWS, oral commun., 2010).

In the last 20 years, wild pig populations have expanded markedly throughout the Southeastern United States (Comer and Mayer, 2009). One explanation of the expansion is biological: wild pig populations have reached a critical mass and are demonstrating exponential growth as they colonize new areas. A second explanation is that much of the range expansion that has occurred over the last 20 years is a product of human-caused colonization - the illegal translocation of wild pigs to establish new populations for hunting (Comer and Mayer, 2009). A study designed to monitor the daily, seasonal, and annual movements of wild pigs could provide insight into which of these reasons for range expansion is more likely and could aid in the development of management plans for wild pig control. A concerted, disciplined, professional approach to wild pig removals is lacking in the Southern United States (Comer and Mayer, 2009). From 2011 to 2013, the U.S. Geological Survey investigated spatial and temporal movements of wild pigs (that is, to better understand wild pig behavior) in order to facilitate an effective approach to wild pig control efforts in Mississippi and Louisiana; more information regarding wild pig populations, their habitat use, and movements at a landscape level is needed.

\section{Methodology}

Global Positioning System (GPS) satellite hybrid radio telemetry devices were attached to 21 wild pigs (weighing 54-136 kilograms $[\mathrm{kg}]$ ) that were captured with trained dogs and were released at the capture sites (fig. 1). These GPS satellite collar devices have an average battery life of 2 years at a data collection interval of 1 hour. The GPS satellite collar devices collected hourly data including date, time, air temperature, and position and transmitted those readings via the Iridium satellite until battery life was exhausted or the collar fell off. Although telemetry devices were procured from two vendors (Lotek and Telemetry Solutions), the manufacturers' claimed 2-year endurance was not achieved. None of the transmitters in our study made that milestone, 


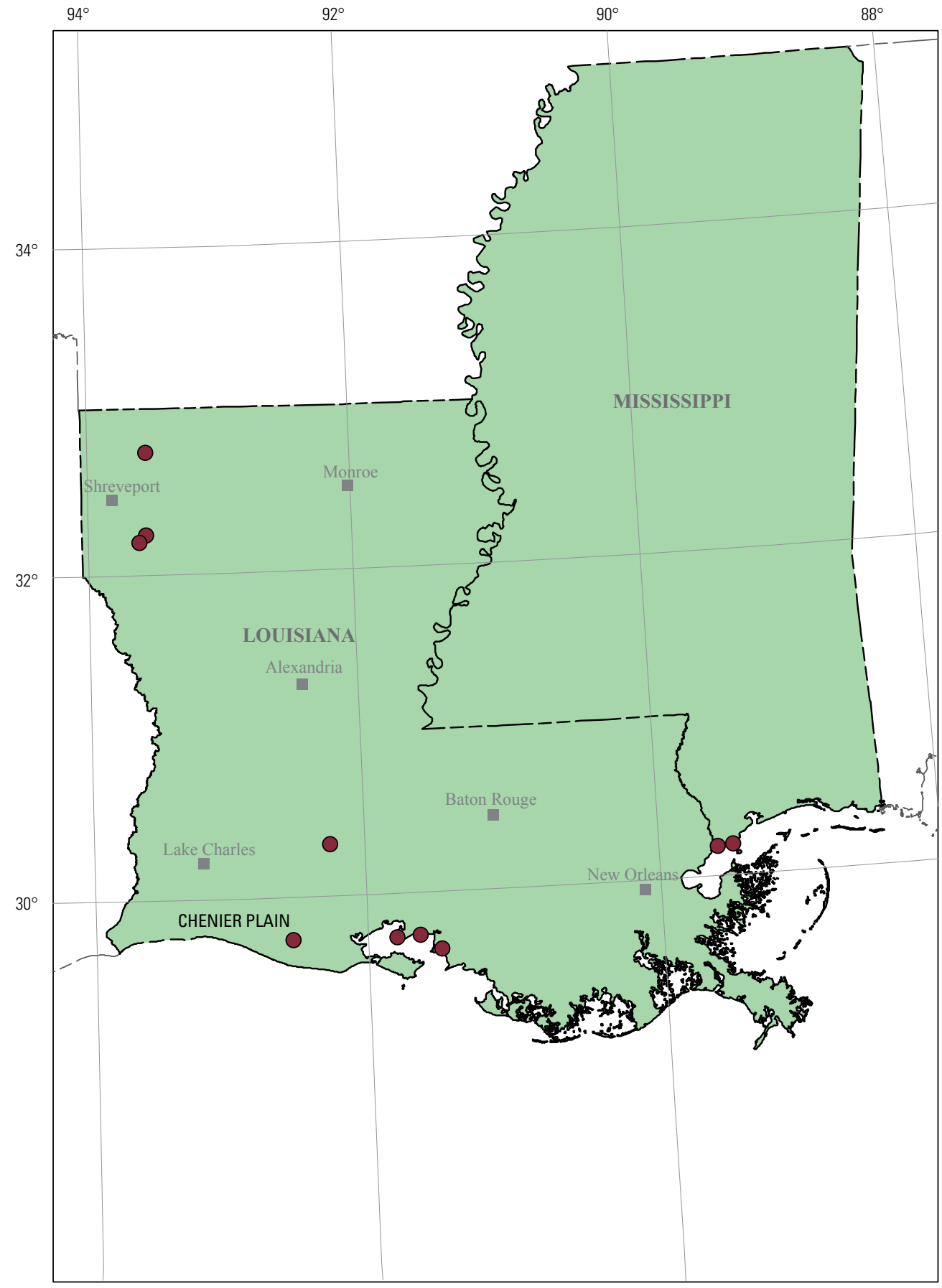

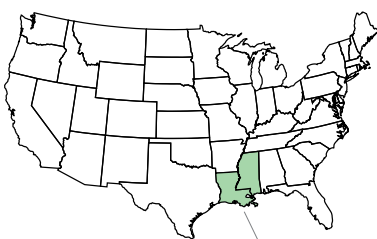

Study area

EXPLANATION

Capture and release site

Base modified from U.S. Geological Survey digital data, 1:2,000,000

Albers Equal-Area Conic projection

North American Datum of 1983

Figure 1. Study area and sites of capture and release of wild pigs (Sus scrofa) fitted with satellite Global Positioning System (GPS) tracking collars during the 2011-13 study in Louisiana and Mississippi. 
with most lasting less than 4 months before going offline or falling off. All data from failed systems and from those that fell off prematurely were recoverable; this was critical in selecting a vendor. Study sites included agricultural, forest, and marsh regions in Louisiana and Mississippi (fig. 1).

The study sites in both States were considered to have high densities of wild pigs. This study was conducted over a 3-year period.

Statistical analyses of variance (ANOVA) and covariance (ANCOVA) were used to determine the relation among distance traveled and time of the day, air temperature (degrees Celsius $\left[{ }^{\circ} \mathrm{C}\right]$ ), and solar and lunar phases. Relations of wild pig movements due to air temperature within and between seasons (spring [Mar--May], summer [June-Aug.], fall [Sept.-Nov.], and winter [Dec.-Feb.]) were analyzed by using partial correlations and Tukey's honestly significant difference (HSD) tests. A t-test was conducted to determine if significant differences existed in average movement patterns between boars and sows. We used a p-value $(P)$ of less than or equal to 0.05 to conclude statistical significance. Spatial data were analyzed by using Esri ArcMap 10.1, and SAS 9.3 and SAS STAT 12.1 (SAS Institute Inc., 2012) were used when analyzing higher order ANOVA and multiple comparison tests. To control for the effect of outliers, only wild pigs that were tracked for more than 3 days were used in the analysis.

Use of GPS satellite hybrid radio telemetry facilitates remote computer monitoring of the movement of wild pigs. The "Judas pig" technique is a method in which a wild pig is captured and collared with a tracking device and released at the site of capture to be relocated at future dates. Through the use of this monitoring technique, the Judas pig will reveal individual movements and positions on the landscape so that it and potentially entire associated sounders (family groups) can be located.

\section{Results}

\section{Statistical Analysis}

We collected 16,674 hourly data points related to date, time, air temperature, and position from 21 GPS-collared wild pigs ( 15 boars and 6 sows; 1 barrow was collared but not used in data analysis) from August 3, 2011, until May 16, 2013. Solar and lunar data, such as sun and moon phases and azimuth angles, were collected and analyzed by using Pearson's correlation and regression analysis; however, these data did not show any significant relations with movements among wild pigs. Table 1 includes the summary statistics of distances traveled by wild pigs (separated by gender and season) during the 3-year study period. Sow data could not be retrieved for fall seasons of 2011 and 2012. We found that, on average, the GPS-collared wild pigs traveled longer distances in summer and winter of 2011 and 2013 than in all four seasons of 2012 (table 1).

Boars tended to travel more than sows, regardless of the season. Sows tended to travel more in summer than in winter and spring, whereas boars traveled more in winter. Coefficients of variation (table 1) reveal that sows have a lower average travel distance during winter but have greater variation. This could be due to a few large but infrequent distance values. A similar pattern was observed in which sow movements were considerably lower in spring and winter when average air temperature is below $20^{\circ} \mathrm{C}$ (fig. 2). Boars did not show any distinctive movement pattern regarding seasonal variation except slightly greater activity in winter (figs. 2 and 3). Moreover, during all 3 years, average movements in fall and spring were less than in summer and winter (fig. 2).

Table 1. Seasonal average distance traveled per hour by collared wild pigs (Sus scrofa) and onsite air temperature recorded from hourly monitoring data during the 2011-13 study in Louisiana and Mississippi.

[m, meters; ${ }^{\circ} \mathrm{C}$, degrees Celsius; $\mathrm{CV}(\%)$, coefficient of variation measured in percent]

\begin{tabular}{|c|c|c|c|c|c|c|c|c|}
\hline \multirow[b]{2}{*}{ Season } & \multirow[b]{2}{*}{ Sex } & \multirow{2}{*}{$\begin{array}{c}\text { Hourly } \\
\text { data points }\end{array}$} & \multicolumn{3}{|c|}{ Distance (m) } & \multicolumn{3}{|c|}{ Temperature $\left({ }^{\circ} \mathrm{C}\right)$} \\
\hline & & & Mean & $\begin{array}{c}\text { Standard } \\
\text { error }\end{array}$ & CV (\%) & Mean & $\begin{array}{c}\text { Standard } \\
\text { error }\end{array}$ & CV (\%) \\
\hline \multirow{2}{*}{$\begin{array}{l}\text { Spring } \\
\text { (Mar.-May) }\end{array}$} & Boar & 3,061 & 90.47 & 5.16 & 315.72 & 23.18 & 0.11 & 26.94 \\
\hline & Sow & 356 & 29.27 & 2.95 & 190.06 & 19.08 & 0.48 & 47.35 \\
\hline \multirow{2}{*}{$\begin{array}{l}\text { Summer } \\
\text { (June-Aug.) }\end{array}$} & Boar & 2,270 & 86.34 & 4.02 & 222.01 & 31.66 & 0.09 & 13.46 \\
\hline & Sow & 477 & 104.87 & 8.99 & 187.22 & 29.23 & 0.20 & 15.14 \\
\hline \multirow{2}{*}{$\begin{array}{l}\text { Fall } \\
\text { (Sept.-Nov.) }\end{array}$} & Boar & 4,476 & 81.61 & 2.89 & 237.02 & 24.33 & 0.11 & 30.05 \\
\hline & Sow & 0 & 0.00 & 0.00 & 0.00 & 0.00 & 0.00 & 0.00 \\
\hline \multirow{2}{*}{$\begin{array}{l}\text { Winter } \\
\text { (Dec.-Feb.) }\end{array}$} & Boar & 5,120 & 127.02 & 4.37 & 246.39 & 18.28 & 0.08 & 33.04 \\
\hline & Sow & 914 & 32.44 & 4.30 & 400.64 & 19.72 & 0.22 & 33.36 \\
\hline
\end{tabular}




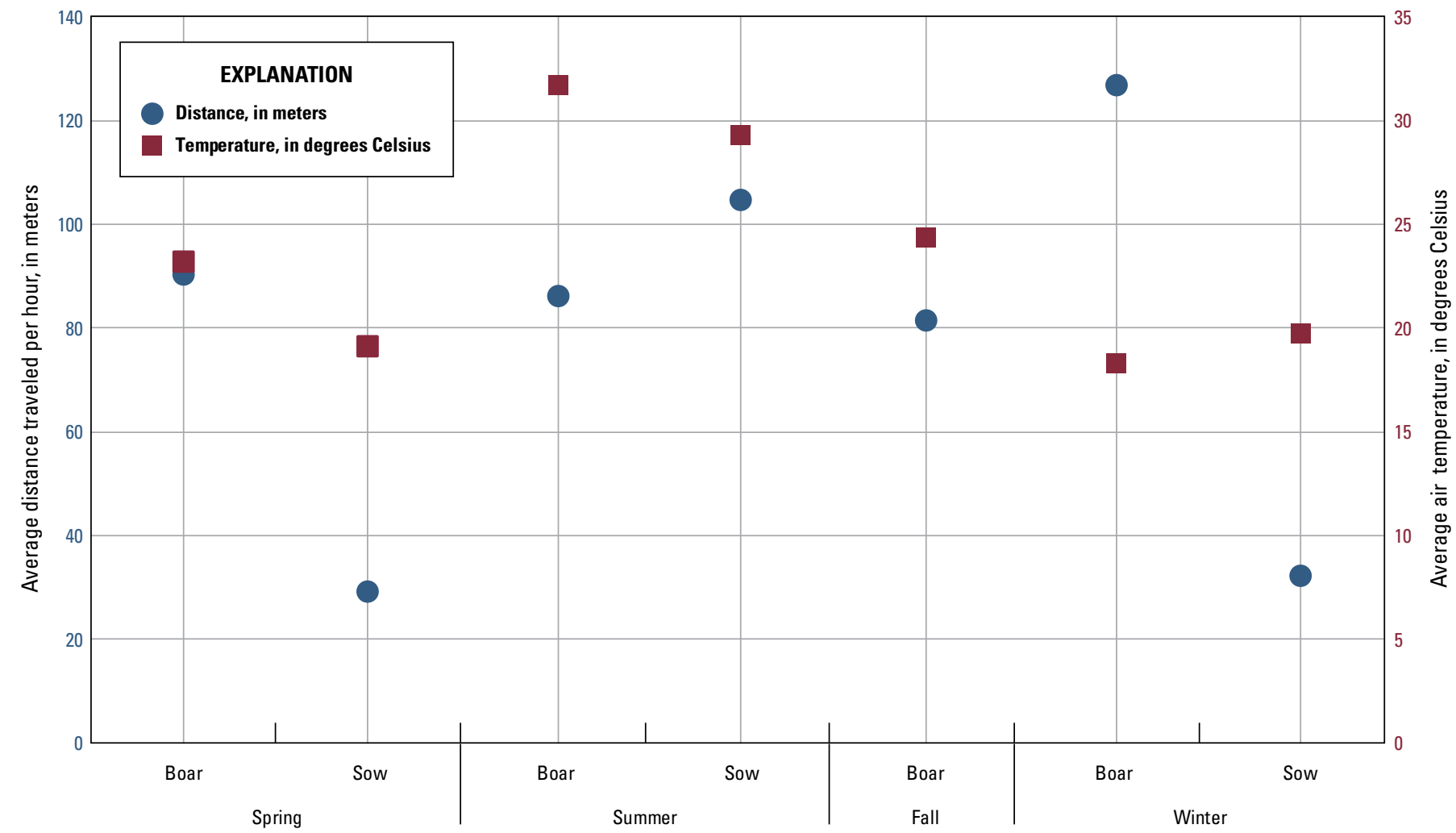

Season

Figure 2. Average distance traveled per hour by collared wild pigs (Sus scrofa) and average air temperature by season during the 2011-13 study in Louisiana and Mississippi.

Boars and sows tended to cover more distance from 0400 hours to 1000 hours or after 1600 hours to 0200 hours (fig. 4). Average air temperatures ranged between $16.8^{\circ} \mathrm{C}$ at 0500 hours and $31.1^{\circ} \mathrm{C}$ at 1200 hours. The general tendency of travel by both genders is late afternoon until early morning (greatest average hourly distance covered by boar was 162 meters [m] at 2300 hours and by sow was $96 \mathrm{~m}$ at 0600 hours) (fig. 4).

A t-test with a Satterthwaite-test criterion for unequal variances (SAS Institute Inc., 2012) revealed that the average hourly movements between boars $(99.72 \pm 2.12 \mathrm{~m})$ and sows $(51.57 \pm 3.47 \mathrm{~m})$ were highly significant $(P<0.001)$. A one-way ANOVA utilizing Tukey's HSD test (SAS Institute Inc., 2012) showed that average distance covered by wild pigs in winter $(112.70 \pm 3.79 \mathrm{~m})$ was greater $(P<0.05)$ than in the three other seasons: spring $(84.10 \pm 4.65 \mathrm{~m})$, summer $(89.56 \pm 3.67 \mathrm{~m})$, and fall $(81.61 \pm 2.89 \mathrm{~m})$.

Sex and season interacted for movement comparisons $(P<0.001)$; therefore, to distinguish which interaction effect differed from another, multiple comparison tests were conducted. All standard multiple comparison tests (Duncan, Student-Newman-Keuls, Tukey, Bonferroni) suggested that boar winter traveling patterns were greater than spring, summer, and fall movements, whereas sows showed significantly lower movements in spring and winter than in summer. Except for summer (when boars and sows did not exhibit any statistically significant differences $[P=0.056]$ in movement), there existed a very significant difference $(P<$ 0.001 ) in movement patterns between genders.

Effects of air temperature on movement patterns of these wild pigs were evaluated by correlating average distances traveled within a 24-hour period and the corresponding average air temperature. Regardless of gender, the Pearson's correlation coefficient $(r=-0.74, P<0.001)$ suggested a significant inverse relation between wild pig movements and air temperature (fig. $5 ; n=24, r^{2}=0.54$ with $P<0.001)$.

The air temperature effect separating genders yielded a significant negative correlation $(r=-0.70, P<0.001)$ among boars, but it was not significant $(r=-0.34, P<0.11)$ among sows. This finding suggests that sows are more tolerant of higher air temperatures or that sows move less than do boars, as documented by the Duncan multiple range test $(n=24$, average distance traveled within 1 hour for boars was $98.34 \mathrm{~m}$, compared to average distance traveled within 1 hour for sows, $50.86 \mathrm{~m}, P<0.05)$. 


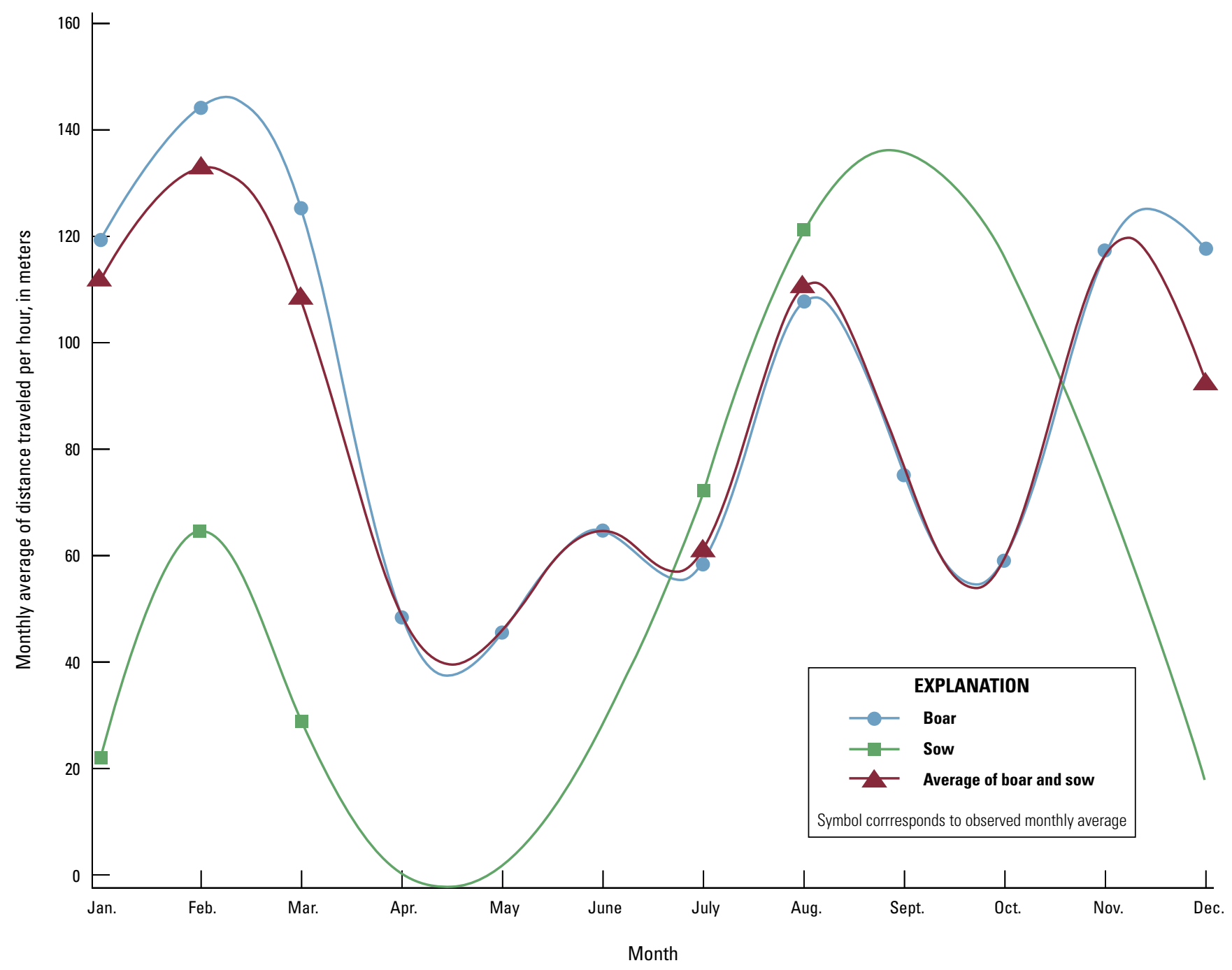

Figure 3. Monthly average of distance traveled per hour by collared wild pigs (Sus scrofa) during the 2011-13 study in Louisiana and Mississippi.

\section{Geospatial Analysis}

Although average movements of wild pigs, either regarding gender (boar or sow) or time (hourly, monthly, and [or] seasonally), showed a range of less than $200 \mathrm{~m}$, the maximum distances traveled by individual wild pigs in specific circumstances differed greatly. Wild pigs traveled less than $500 \mathrm{~m} 95$ percent of the time, with less than 1.5 percent of the data indicating more than 1 kilometer $(\mathrm{km})$ of distance covered within 1 hour (table 2). Maximum travel distance was as much as $6 \mathrm{~km}$, with a maximum modal range of $2-3 \mathrm{~km}$ (fig. 6).

The geospatial modeling environment (GME) program was used to provide information on the movements of wild pigs. Wild pig movement boundaries were analyzed by using the "GENMCP" function within the GME program (Beyer, 2014). The GENMCP function yielded a minimum convex polygon (MCP), which serves as a proxy of home range (where an animal lives and travels), of each collared wild pig. Regardless of marsh or nonmarsh area, average MCP for boars showed an area of 911 hectares (ha) (range of 47-3,689 ha), whereas for sows, it was 116 ha (range of 5.7-399 ha).

Boars in Mississippi and Louisiana marsh habitat have similar MCP values (about 900 ha), whereas sows in Mississippi marsh habitat yielded an MCP value of about 60 ha. Movements of collared boars in nonmarsh habitat (for example, forest and agricultural lands) in Louisiana indicated an MCP value four times greater than that for boars in marsh habitat. There were no data collected in this study from collared sows in marsh habitat in Louisiana or from collared boars in nonmarsh habitat in Mississippi, so we were unable to examine these relations. The MCPs suggest that when a wild pig is seen it will have a home range of approximately the area represented in the MCP values. Although MCPs have a tendency of overestimating the size of home range (Burgman and Fox, 2003), they provide a conservative approach to the risk assessment of potential infestations of wild pigs. 


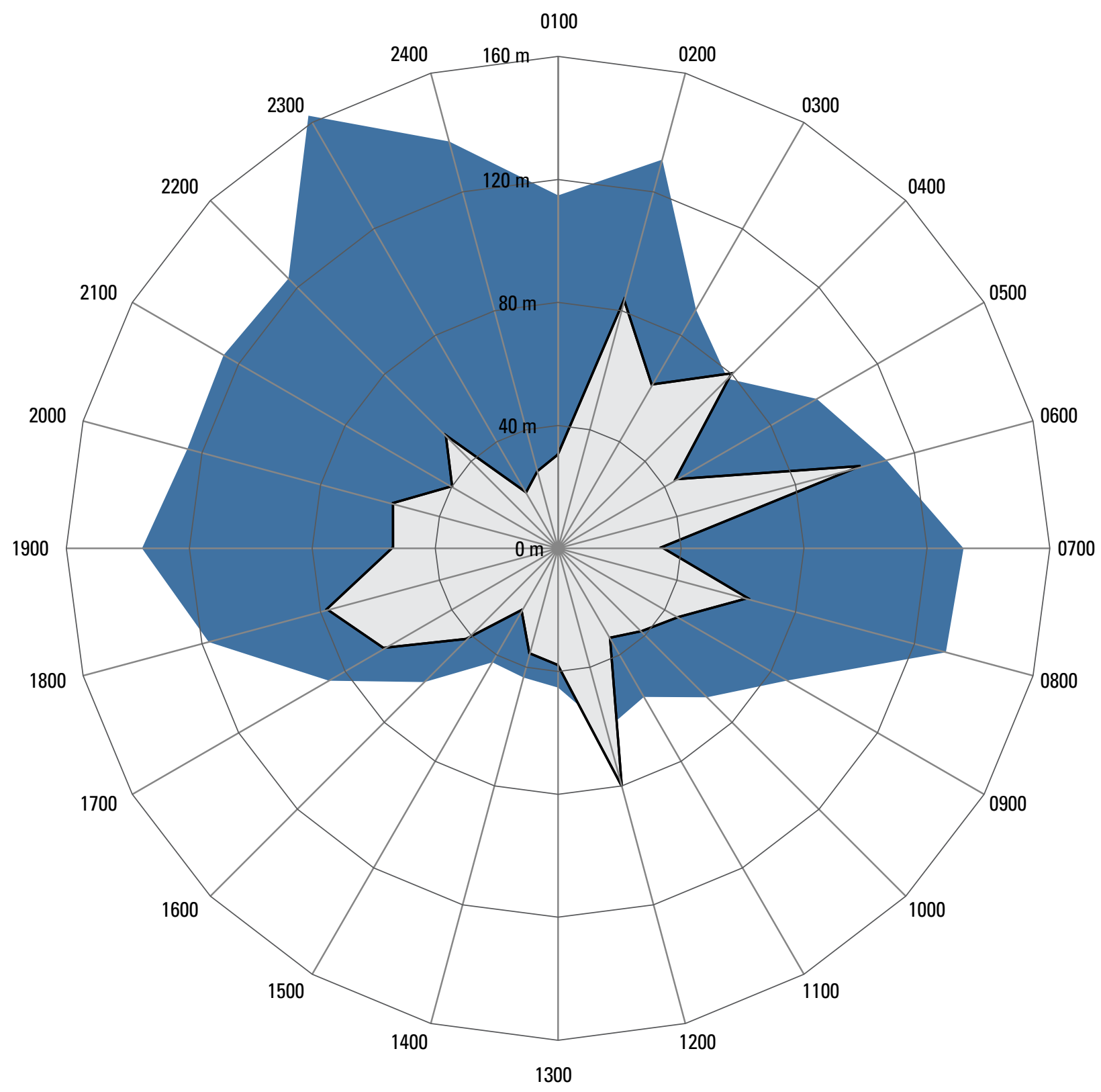

EXPLANATION

Distance traveled by boar

Distance traveled by sow

$\mathrm{m}$, meter

Figure 4. Average distance traveled by collared wild pigs (Sus scrofa) on an hourly basis during 24-hour periods and depicting diurnal effect in movement during the 2011-13 study in Louisiana and Mississippi. 


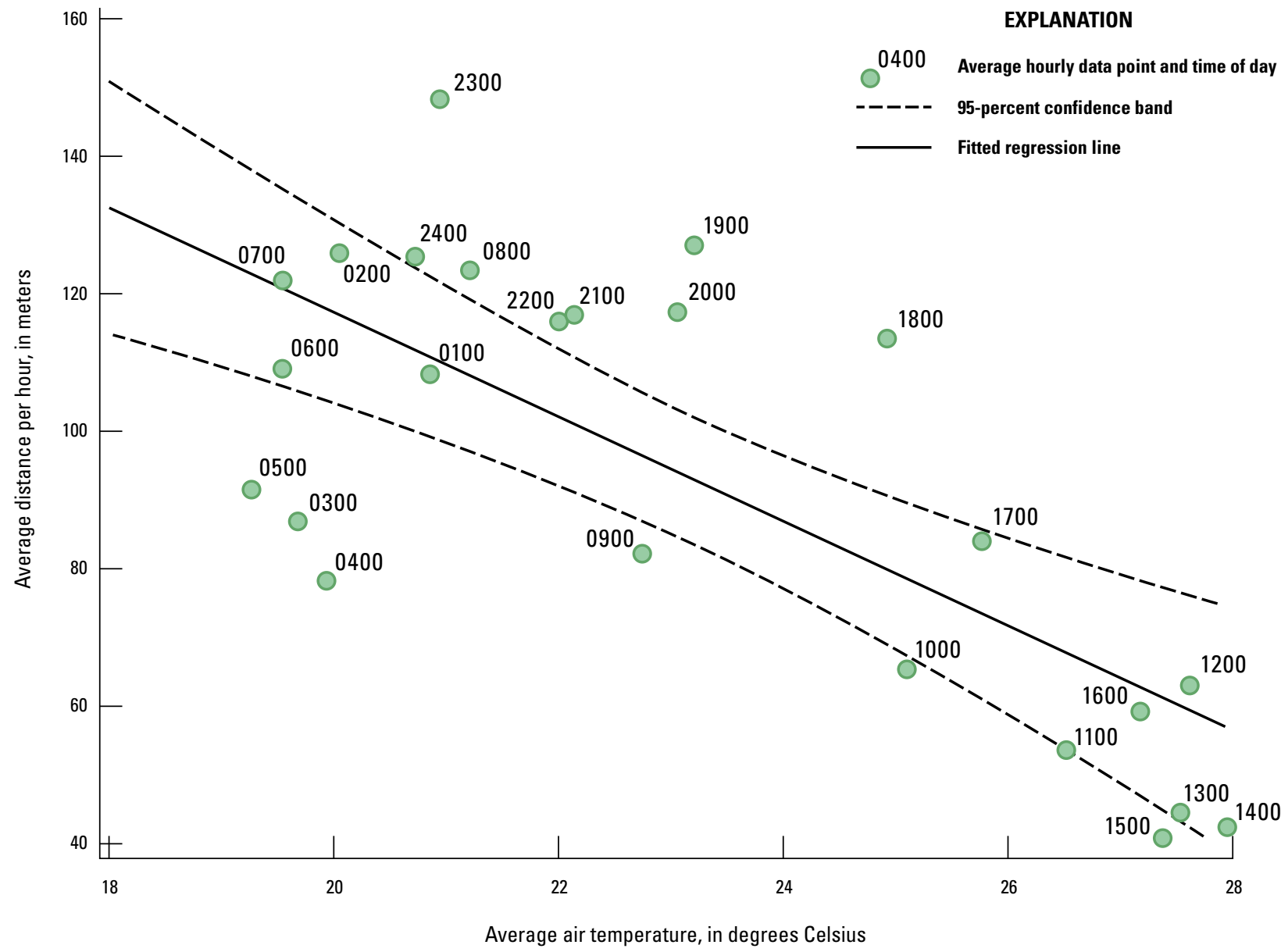

Figure 5. Regression with a 95-percent confidence band showing average distance per hour traveled by wild pigs (Sus scrofa) relative to average air temperature during a 24-hour period during the 2011-13 study in Louisiana and Mississippi.

Table 2. Distance traveled per hour by wild pigs (Sus scrofa) in interval frequency during the 2011-13 study in Louisiana and Mississippi.

[m, meters]

\begin{tabular}{lcccc}
\hline \multicolumn{1}{c}{ Distance $(\mathbf{m})$} & Frequency & Percent & Cumulative frequency & Cumulative percent \\
\hline $\mathbf{0 - 2 5}$ & 9,921 & 59.50 & 9,921 & 59.50 \\
$\mathbf{2 5 - 5 0}$ & 1,710 & 10.26 & 11,631 & 69.76 \\
$\mathbf{5 0 - 1 0 0}$ & 1,645 & 9.87 & 13,276 & 79.62 \\
$\mathbf{1 0 0 - \mathbf { 2 0 0 }}$ & 1,431 & 8.58 & 14,707 & 88.20 \\
$\mathbf{2 0 0}-\mathbf{5 0 0}$ & 1,278 & 7.66 & 15,985 & 95.87 \\
$\mathbf{5 0 0 - 1 , 0 0 0}$ & 452 & 2.71 & 16,437 & 98.58 \\
Greater than 1,000 & 237 & 1.42 & 16,674 & 100.00 \\
\hline
\end{tabular}




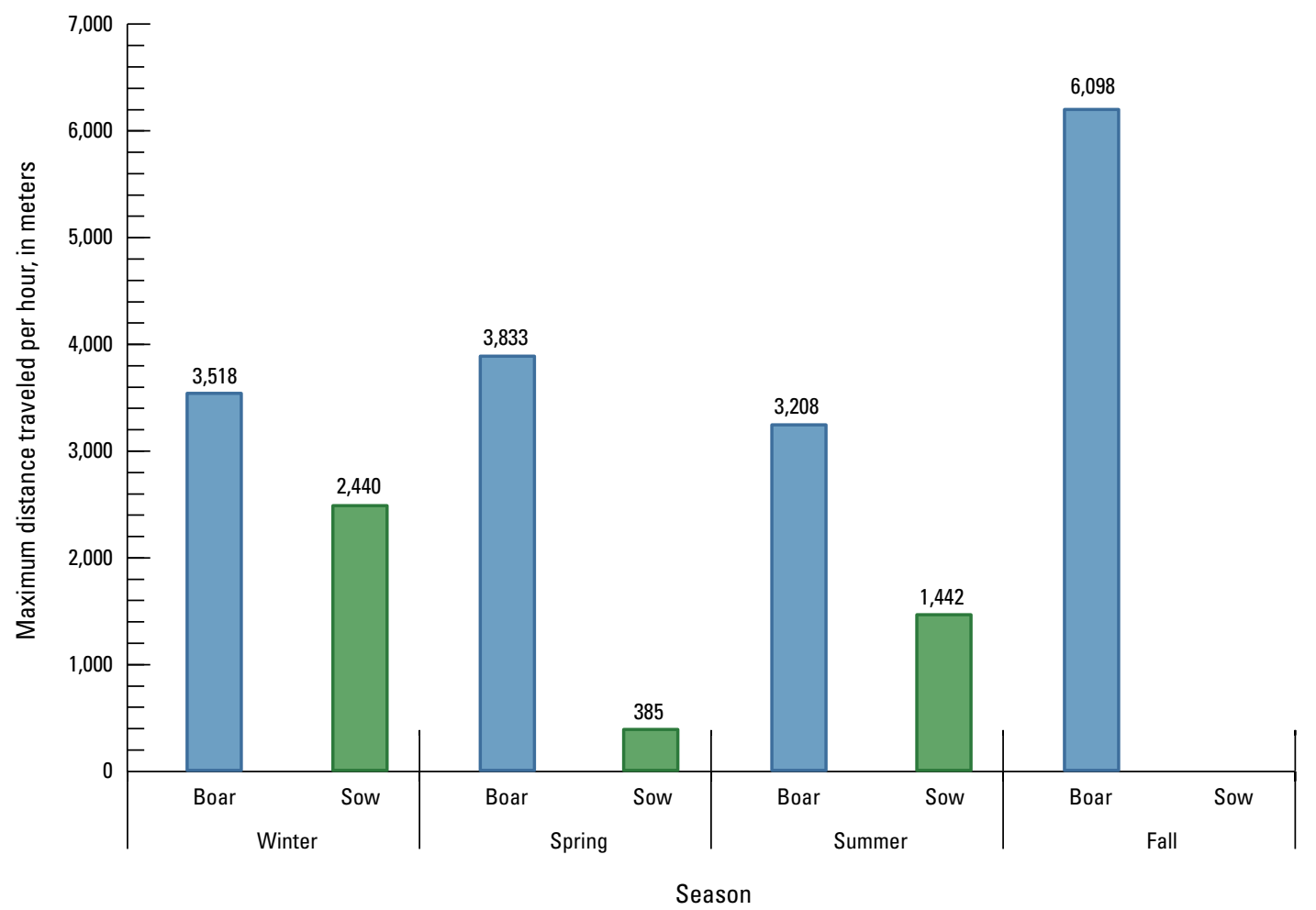

Figure 6. Maximum distance traveled per hour by wild pigs (Sus scrofa) with respect to gender and season during the 2011-13 study in Louisiana and Mississippi.

\section{Discussion}

In this study, the feasibility of the Judas pig technique was successfully tested on only one boar in the Louisiana marsh; hence, the Judas pig technique is not central to this study. Interesting results, however, were obtained. This boar was used as a Judas pig, and 24 associated wild pigs were located in 1 day by tracking this boar until it was removed. At two other locations, the tracking data from the collared wild pigs were used to focus removal efforts, but the Judas pig technique was not strictly employed. The usage of Judas pig technique shows that it can be a valuable management control tool.

Understanding wild pig range activity is crucial when developing a management plan to control populations. Home range expansion in a broad sense entails moving among locations to secure better resources and (or) environmental conditions. In the case of invasive wild pigs, these opportunistic movements translate into economic and natural resource losses. Telemetry data provide accurate locations of movement corridors and areas (hot spots) that are used intensively by wild pigs, thus providing useful information for wild pig management. Understanding wild pig movements at all levels is critical to responding to invasions.
Hayes and others (2009) used radio telemetry to assess movements of wild pigs in Mississippi. They reported that dry-season home ranges were larger (640 ha) than wet-season home ranges (300 ha) in a magnitude similar to this study. Schlichting and others (2012) in their satellite tracking study found MCPs in the more arid areas of Texas and Oklahoma of 4,100 and 2,900 ha, respectively. Chuelo (2012) reported Missouri wild pigs with an average home range of 2,400 ha. When compared to those in our study, wild pigs in the more arid climates have consistently greater home ranges.

We believe that one of the major factors contributing to the recent increase of wild pig populations in Louisiana and Mississippi is the aftermath of several catastrophic hurricanes that passed through these States within the last 10 years, including most notably hurricanes of 2005 (Katrina and Rita) and 2008 (Ike and Gustav) (B.L. Goatcher, USFWS, oral commun., 2010). For several years, following the passing of these hurricanes access was limited in coastal impact zones to wild pig hunters because of the downed timber and debris wracks (B.L. Goatcher, USFWS, oral commun., 2010). Additionally, hurricane and tornado thinning of woodlands and removing of forest canopies allowed sunlight to penetrate to the ground, encouraging dense growths of briars and deer peas (Vigna luteola) and providing additional escape cover 
and forage vegetation species that support wild pigs (B.L. Goatcher, USFWS, oral commun., 2010). Other significant contributions to population increases of wild pigs are presumed illegal relocations of these animals by humans and the fragmentation of land parcels (B.L. Goatcher, USFWS, oral commun., 2010).

Wild pigs in this study trended towards a crepuscular or nocturnal activity pattern, and home ranges were relatively limited compared to tracking studies elsewhere (911 ha for boars and 116 ha for sows). These limited home ranges, personal knowledge of past illegal relocations, and all published sources used in this research suggest that natural movements of wild pigs are not a major factor in the current range expansions. Any natural wild pig population and range changes are overshadowed by the rare but significant weatherrelated transfers (such as floods and hurricanes) that seed new populations and the illegal relocations and stocking of these animals by humans (Mayer, 2009).

It may be of interest to investigate why sows traveled more in summer and boars traveled more in winter. We postulate that, in general, sows in our populations move longer distances in summer because they are not hindered by neonatal piglets delivered during winter and spring. Comer and Mayer (2009) found that most populations show prominent peaks in farrowing in winter and spring, but farrowing varies depending on food availability and other environmental conditions. As for boars traveling longer distances in the winter, we speculate that they must travel longer distances to find mates because sows are less mobile during farrowing.

Future work on movements of wild pigs might include studying the distance a wild pig travels after being relocated from a capture site to a new location with wild pigs and without wild pigs or the amount of time it takes for a wild pig to reestablish a new home range. These answers will probably depend on the age of the animal, social rank of the animal, and quality and configuration of habitat on the landscape (such as marsh versus upland/agriculture). These studies could help management and lawmakers make more informed decisions regarding the presumed illegal transportation and control of wild pigs.

\section{Summary}

Wild pigs (Sus scrofa) are a major problem for land and resource managers in the United States because of the enormous amounts of damage that these animals cause to natural and man-made environments. This invasive species is found in large populations on public and private lands in most States. Their high reproductive potential, ability to adapt to numerous environments, destructive foraging habits, and potential to function as disease vectors make wild pigs a challenging and serious threat to environmental, human, and financially important resources in the United States.
From 2011 to 2013, the U.S. Geological Survey investigated spatial and temporal movements of wild pigs to establish an effective approach to wild pig controls in Mississippi and Louisiana; more information regarding wild pig populations, their habitat use, and movements at a landscape level is needed. Global Positioning System satellite hybrid radio telemetry devices were attached to 21 wild pigs that were captured with trained dogs and were released at the capture sites from August 3, 2011, until May 16, 2013. We collected 16,674 hourly data points related to date, time, air temperature, and position from the collared wild pigs. Solar and lunar data, such as sun and moon phases and azimuth angles, were collected and analyzed; however, these data did not show any significant relations with movements among wild pigs. We found that, on average, the GPS-collared wild pigs traveled longer distances in summer and winter of 2011 and 2013 than in all four seasons of 2012. Relations of wild pig movements due to air temperature within and between seasons were analyzed. Movements were significantly correlated negatively with air temperature. Differences in movements between seasons and years were observed. On average, movements of boars were significantly greater than those of sows. Except for summer, there existed a very significant difference in movement patterns between genders. A significant inverse relation between wild pig movements and air temperature was observed between the genders.

Average home range, determined by using a minimum convex polygon as a proxy, was 911 hectares for boars, whereas average home range for sows was 116 hectares. Wild pigs in marsh habitat traveled lesser distances relative to those from more arid, nonmarsh habitats. Overall, results of this study indicate that wild pigs in Louisiana and Mississippi have small home ranges. These small home ranges suggest that natural movements have not been a major factor in the recent broadscale range expansion observed in this species in the United States.

\section{References Cited}

Beyer, H.L., 2014, Introducing the geospatial modelling environment-Overview: Spatial Ecology, LLC, accessed April 7, 2014, at http://www.spatialecology.com/gme.

Burgman, M.A., and Fox, J.C., 2003, Bias in species range estimates from minimum convex polygons-Implications for conservation and options for improved planning: Animal Conservation, v. 6, no. 1, p. 19-28.

Chuelo, A., 2012, Feral hogs in Missouri, in 2012 International Wild Pig Conference, Science and Management, April 15-18, 2012, San Antonio, Texas: Mississippi State University Extension Service, accessed April 7, 2014, at http:// wildpigconference.com $/ \mathrm{pdf} / 2012 \% 20$ International $\% 20$ Wild\%20Pig\%20Conference\%20Program.pdf. 
Comer, C.E., and Mayer, J.J., 2009, Wild pig reproductive biology, in Mayer, J.J., and Brisbin, I.L., Jr., eds., Wild pigs-Biology, damage, control techniques, and management: Aiken, South Carolina, Savannah River National Laboratory, SRNL-RP-2009-00869, p. 51-75.

Elsey, R.C., Mouton, E.C., Jr., and Kinler, N., 2012, Effects of feral swine (Sus scrofa) on alligator (Alligator mississippiensis) nests in Louisiana: Southeastern Naturalist, v. 11, no. 2, p. 205-218.

Hamrick, B., Smith, M., Jaworowski, C., and Strickland, B., 2011, A landowner's guide for wild pig managementPractical methods for wild pig control: Mississippi State University Extension Service and Alabama Cooperative Extension System, Alabama A\&M University, and Auburn University, $43 \mathrm{p}$.

Hayes, R., Riffell, S., Minnis, R., and Holder, B., 2009, Survival and habitat use of feral hogs in Mississippi: Southeastern Naturalist, v. 8, no. 3, p. 411-426.

Kaller, M.D., and Reed, D., 2010, Invasive feral swine in Louisiana: LSU AgCenter Research and Extension, Louisiana Agriculture Magazine, v. 53, no. 4, p. 16-19, accessed April 7, 2014, at http://text.lsuagcenter.com/en/ communications/publications/agmag/Archive/2010/fall/ Invasive-Feral-Swine-in-Louisiana.htm.

Mayer, J.J., 2009, Wild pig reproductive biology, in Mayer, J.J., and Brisbin, I.L., Jr., eds., Wild pigs-Biology, damage, control techniques, and management: Aiken, S.C., Savannah River National Laboratory, SRNL-RP-200900869, p. 77-104, 221-246.
Mayer, J.J., and Brisbin, I.L., Jr., 1993, Distinguishing feral hogs from introduced wild boar and their hybrids - A review of past and present efforts, in Hanselka, C.W., and Cadenhead, J.F., eds., Feral swine-A compendium for resource managers: Texas Agricultural Extension Service, San Angelo, Tex., p. 28-49.

Mayer, J.J., Hamilton, R.E., and Brisbin, I.L., Jr., 2009, Wild pig reproductive biology, in Mayer, J.J., and Brisbin, I.L., Jr., eds., Wild pigs - Biology, damage, control techniques, and management: Aiken, S.C., Savannah River National Laboratory, SRNL-RP-2009-00869, p. 275-288.

Mayer, J.J., and Moore-Barnhill, L.A., 2009, Wild pig reproductive biology, in Mayer, J.J., and Brisbin, I.L., Jr., eds., Wild pigs - Biology, damage, control techniques, and management: Aiken, S.C., Savannah River National Laboratory, SRNL-RP-2009-00869, p. 331-340.

SAS Institute Inc., 2012, SAS software 9.3: Cary, N.C., SAS Institute Inc., proprietary software licensed to U.S Geological Survey.

Schlichting, P., Gipson, P., Dabbert, B., Smith, T., Cagle, K., and Deurmyer, C., 2012, Habitat utilization by wild pigs on military lands in Texas and Oklahoma, in 2012 International Wild Pig Conference, Science and Management, April 15-18, 2012, San Antonio, Texas: Mississippi State University Extension Service, accessed April 7, 2014, at http://wildpigconference.com/pdf/2012\%20International $\% 20$ Wild\%20Pig\%20Conference\%20Program.pdf.

West, B.C., Cooper, A.L., and Armstrong, J.B., 2009, Managing wild pigs - A technical guide: Human-Wildlife Interactions Monograph, no. 1, p. 1-55. 



\section{$\frac{2}{8}$}

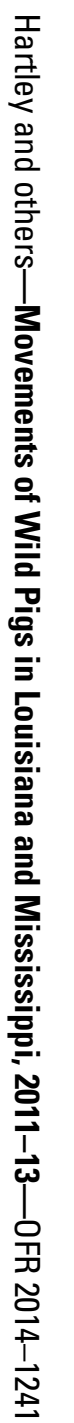

